\title{
Multi-Evaporator Miniature Loop Heat Pipe for Small Spacecraft Thermal Control
}

\author{
Jentung $\mathrm{Ku}^{1}$, Laura Ottenstein ${ }^{2}$, Donya Douglas ${ }^{3}$ \\ NASA Goddard Space Flight Center \\ Greenbelt, Maryland 20771
}

This paper presents the development of the Thermal Loop experiment under NASA's New Millennium Program Space Technology 8 (ST8) Project. The Thermal Loop experiment was originally planned for validating in space an advanced heat transport system consisting of a miniature loop heat pipe (MLHP) with multiple evaporators and multiple condensers. Details of the thermal loop concept, technical advances and benefits, Level 1 requirements and the technology validation approach are described. An MLHP breadboard has been built and tested in the laboratory and thermal vacuum environments, and has demonstrated excellent performance that met or exceeded the design requirements. The MLHP retains all features of state-of-the-art loop heat pipes and offers additional advantages to enhance the functionality, performance, versatility, and reliability of the system. In addition, an analytical model has been developed to simulate the steady state and transient operation of the MHLP, and the model predictions agreed very well with experimental results. A protoflight MLHP has been built and is being tested in a thermal vacuum chamber to validate its performance and technical readiness for a flight experiment.

Nomenclature
$Q_{\text {High }}=$ highest power to the evaporator while maintaining the compensation chamber temperature at $T_{S E T}$
$Q_{\text {Low }}=$ lowest power to the evaporator while maintaining the compensation chamber temperature at $T_{S E T}$
$T_{S E T}=$ compensation chamber set point temperature

\section{Introduction}

A loop heat pipe (LHP) is a very versatile heat transfer device which can transport a large amount of heat over a long distance with a small temperature difference [1, 2]. LHPs have been used for thermal control of many commercial communications satellites and NASA's spacecraft, including ICESAT, AURA, SWIFT, and GOES [3-5]. All LHPs currently servicing orbiting spacecraft have a single evaporator with a $25-\mathrm{mm}$ outer diameter primary wick. When the heat source has a large thermal footprint, or several heat sources need to be controlled at similar temperatures, an LHP with multiple evaporators is highly desirable. For small spacecraft applications, miniaturization of the LHP is necessary in order to meet the stringent requirements of low mass, low power and compactness. Also important in the thermal subsystem development is the need for design flexibility which allows for optimum placement of components. Under NASA's New Millennium Program Space Technology 8 (ST8) Project, the Thermal Loop experiment would validate in space the performance of a miniature loop heat pipe (MLHP) with multiple evaporators and multiple condensers. Each evaporator has a primary wick with an outer diameter of $6.35 \mathrm{~mm}$.

Under NASA's New Millennium Program, the Thermal Loop experiment was required to advance its technology readiness level (TRL) from 3 to 7 , i.e. to advance the maturity of the technology from "proof of concept" to "demonstrating performance in space with a prototype." An MLHP Breadboard has been built and tested in the laboratory and thermal vacuum environments for TRL 4 and 5 validations, respectively. The MLHP Breadboard demonstrated excellent performance that met or exceeded all requirements. In addition, an analytical model has been developed to simulate the steady state and transient operation of the MLHP. The model predictions agreed very well with experimental results in laboratory and thermal vacuum testing.

\footnotetext{
${ }^{1}$ Group Leader, Thermal Engineering Branch, Goddard Space Flight Center, Greenbelt, Maryland, USA, AIAA Senior Member.

${ }^{2}$ Aerospace Engineer, Thermal Engineering Branch, Goddard Space Flight Center, Greenbelt, Maryland, USA.

${ }^{3}$ Aerospace Engineer, Instrument Systems Branch, Goddard Space Flight Center, Greenbelt, Maryland, USA.
} 
Because of budget constraints, NASA has cancelled the flight segment of the project. Nevertheless, a protoflight MLHP has been built and is being tested in a thermal vacuum chamber to validate the attainment of TRL 6 and its technical readiness for a space flight experiment. This paper presents the Thermal Loop concept, technical advances and benefits, experiment objectives, Level 1 requirements, and the technical approach for technology validation. In particular, the MLHP Breadboard testing and the analytical model predictions that validated the attainment of TRL 5 of the Thermal Loop technology will be described. The development of the protoflight unit will also be presented.

\section{Thermal Loop Concept}

Figure 1 shows the Thermal Loop experiment concept. At the heart of the Thermal Loop experiment is an MLHP which transports heat loads from the heat sources to the heat sinks while maintaining tight temperature control for all instruments under varying heat load and environmental conditions.

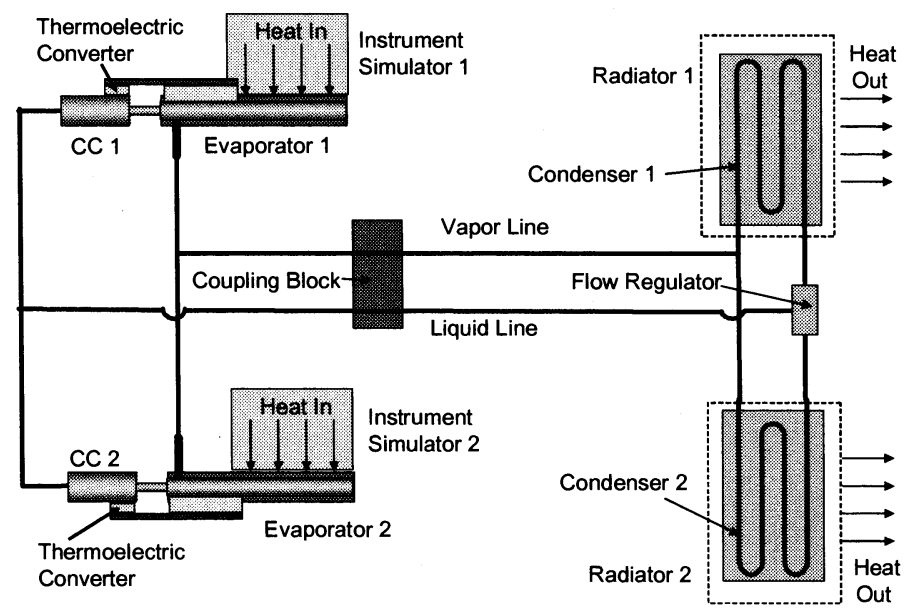

Figure 1. Thermal Loop Experiment Concept

Key features of the Thermal Loop experiment include: 1) multiple evaporators in a single LHP where each evaporator has its own integral compensation chamber (CC); 2) a primary wick with an outer diameter (O.D.) of $6.35 \mathrm{~mm}$ for each evaporator; 3) multiple condensers that are attached to different radiators; 4) a thermoelectric converter (TEC) that is attached to each $\mathrm{CC}$ and connected to the evaporator via a flexible thermal strap; 5) a flow regulator located downstream of the condensers; 6) coupling blocks connecting the vapor line and liquid line; and 7) ammonia working fluid.

\section{Technical Advances and Benefits}

Table 1 summarizes the technical advances and benefits of the Thermal Loop technology. Most comparisons are made in reference to state-of-the-art single-evaporator LHPs. Details are described below.

Multiple Miniature Evaporators: An LHP utilizes boiling and condensation of the working fluid to transfer heat, and surface tension forces developed by the evaporator wick to circulate the fluid [1-2]. This process is passive and self-regulating in that the evaporator will draw as much liquid as necessary to be completely converted to vapor according to the applied heat load. When multiple evaporators are placed in parallel in a single loop, each evaporator will still work passively. No control valves are needed to distribute the fluid flows among the evaporators. All evaporators will produce vapor that has the same temperature as liquid vaporizes inside individual evaporators regardless of their heat loads. The loop works as a thermal bus that provides a single interface temperature for all instruments, and the instruments can be placed at their optimum locations. Furthermore, the instruments that are turned off can draw heat from the instruments that are operational because the evaporators will automatically share heat among themselves $[2,6]$. This will eliminate the need for supplemental electrical heaters while maintaining all instruments close to the loop operating temperature. The heat load sharing function among evaporators is passive and automatic. Therefore, each instrument can operate independently without affecting other instruments. When all instruments are turned off, the loop can be shut down by keeping the $\mathrm{CC}$ at a temperature above the minimum 
allowable instrument temperature. No heat will flow to the condensers/radiators. Thus, the loop works as a thermal switch.

The primary wick in the evaporator has an outer diameter of $6.35 \mathrm{~mm}$. The evaporator mass is therefore reduced by more than 70 percent when compared to the evaporator having a $25 \mathrm{~mm}$ O.D. primary wick used in state-of-the-art LHPs. Small evaporators also reduce the required fluid inventory in the LHP, and the mass and volume of the thermal system.

Table 1. Technical Advances and Benefits of Thermal Loop Technology

\begin{tabular}{|l|l|}
\hline \multicolumn{1}{|c|}{ State-of-the-Art } & \multicolumn{1}{c|}{ ST8 Technical Advance } \\
\hline LHP has a single evaporator & $\begin{array}{l}\text { LHP has multiple evaporators (Thermal Loop will have } \\
\text { two evaporators for demonstration) }\end{array}$ \\
\hline $\begin{array}{l}\text { Requires supplemental heaters to maintain temperatures } \\
\text { of off-instruments }\end{array}$ & $\begin{array}{l}\text { Heat load sharing among evaporators eliminates or } \\
\text { reduces supplemental heater powers }\end{array}$ \\
\hline LHP has 25mm wick & LHP has 6.35mm wick - reduced volume and mass \\
\hline $\begin{array}{l}\text { Top-level transient model for LHPs with a single } \\
\text { evaporator } \\
\text { No scaling rule has been established }\end{array}$ & $\begin{array}{l}\text { Detailed transient model for LHPs with multiple } \\
\text { evaporators } \\
\text { Scaling rules will be established }\end{array}$ \\
\hline $\begin{array}{l}\text { Relies on starter heater on evaporator for start-up } \\
\text { Power required: 20W to 40W }\end{array}$ & $\begin{array}{l}\text { Uses TECs on CCs to ensure successful start-up } \\
\text { Power required: less than 5W }\end{array}$ \\
\hline $\begin{array}{l}\text { Control heater on CC for temperature control - cold } \\
\text { biased, heating only, no cooling, } \\
\text { Heater power: 5W to 20W }\end{array}$ & $\begin{array}{l}\text { TECs on CCs and coupling block on transport lines for } \\
\text { temperature control - heating and cooling } \\
\text { Heater power: 0.5W to 5W }\end{array}$ \\
\hline
\end{tabular}

Multiple Condensers/Flow Regulator: The fluid flow distribution among multiple, parallel condensers is also passive and self regulating $[2,6]$. Each condenser will receive an appropriate mass flow rate so that the conservation laws of mass, momentum and energy are satisfied in the condenser section. If a condenser is fully utilized, such as when the attached radiator is exposed to a warm environment, vapor will be prevented from entering the liquid return line by the capillary flow regulator located downstream of the condensers, and any excess vapor flow will be diverted to other condensers. Thus, no heat will be transmitted from a hot radiator back to the instruments, effecting a thermal diode action.

TECs: The LHP operating temperature is governed by its $\mathrm{CC}$ temperature. The $\mathrm{CC}$ temperature as a function of the evaporator power at a given condenser sink temperature follows the well-known V-shaped curve shown in Figure 2. The resulting temperature curve is the LHP natural operating temperature. The $\mathrm{CC}$ temperature can be controlled at a desired set point temperature of $\mathrm{T}_{\text {set }}$. The state-of-the-art approach is to cold bias the $\mathrm{CC}$ and use electrical heaters to raise the $\mathrm{CC}$ temperature. As shown in Figure 2, the CC temperature can be controlled at $T_{\text {set }}$ between heat loads of $\mathrm{Q}_{\text {Low }}$ and $\mathrm{Q}_{\text {High. }}$ However, this technique does not work for $\mathrm{Q}<\mathrm{Q}_{\text {Low }}$ where the natural operating temperature is higher than the desired set point temperature. The $\mathrm{CC}$ requires cooling instead in order to maintain its temperature at $\mathrm{T}_{\text {set }}$.

A TEC can be attached to the $\mathrm{CC}$ to provide heating as well as cooling to control the CC temperature. One side of a TEC can be attached to the CC, while the other side can be

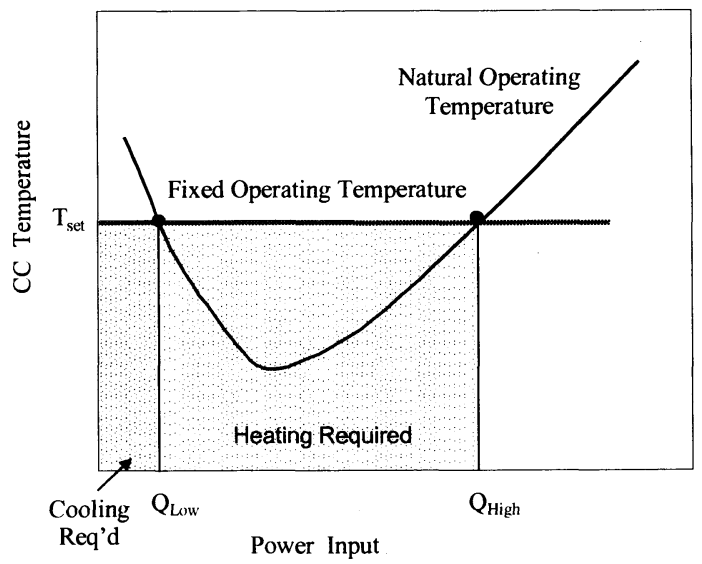

Figure 2. LHP Operating Temperature connected to the evaporator via a flexible thermal strap. When the TEC is cooling the CC, the total heat output from the TEC hot side, i.e. the sum of the power applied to the TEC and the heat pumped out of the CC, is transmitted to the evaporator and ultimately dissipated to the condenser. When the TEC is heating the CC, some heat will be drawn from the evaporator through the thermal strap to the TEC cold side. The sum of the power applied to the TEC and the heat drawn from the evaporator is delivered to the $\mathrm{CC}$. The heat drawn from the evaporator reduces the external power required to heat the $\mathrm{CC}$. The power savings derived from using a TEC can be substantial when compared to 
conventional electric heaters, especially when the evaporator has a high/medium heat load and the condenser is exposed to a very cold environment.

The operating temperature of the MLHP can be maintained by controlling any number of the CCs at the desired set point temperature [7]. Control can also be switched from one CC to another at any time. Furthermore, the CC set point temperature can be changed upon command while the loop is operational. The ability of the CC to control the loop operating temperature at a constant value makes the MLHP function as a variable conductance thermal device.

In addition to maintaining the CC temperature, the TECs can be used to enhance the LHP start-up success. A typical LHP start-up involves raising the CC temperature above the evaporator temperature and then applying power to the evaporator. As the evaporator temperature rises above the $\mathrm{CC}$ temperature by a certain amount (the superheat), vapor bubbles will be generated in the evaporator and the loop will start, as shown in Figure 3(a). However, the required superheat for boiling is stochastic and can range from less than $1 \mathrm{~K}$ to more than $10 \mathrm{~K}$. A high superheat can lead to start-up difficulty because, while the evaporator temperature is rising to overcome the required superheat, the $\mathrm{CC}$ temperature also rises due to the heat leak from the evaporator. Thus, the required superheat for bubble generation may never be attained, as shown in Figure 3(b). This is especially true when a low heat load is applied to the evaporator and a high superheat is required. The net heat load to the evaporator will be small during the start-up transient when the evaporator is attached to an instrument. To overcome the start-up difficulty, the state-of-the-art LHPs use a small-sized starter heater to provide a highly concentrated heat flux to generate first vapor bubbles locally. The required starter heater power is on the order of $30 \mathrm{~W}$ to $60 \mathrm{~W}$ for standard LHPs with a $25 \mathrm{~mm}$ O.D. evaporator. For LHPs with small evaporators, the required starter heater power is estimated to be between $20 \mathrm{~W}$ and $40 \mathrm{~W}$.

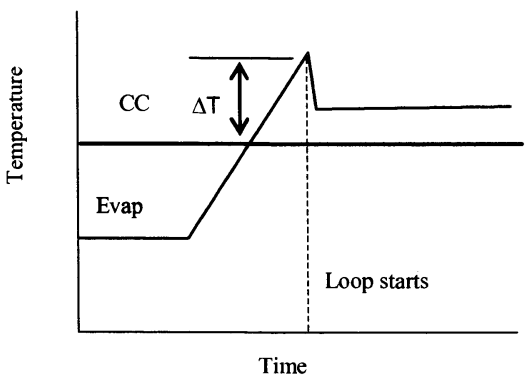

(a)

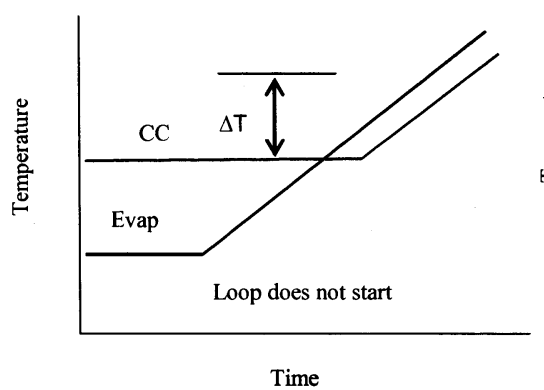

(b)

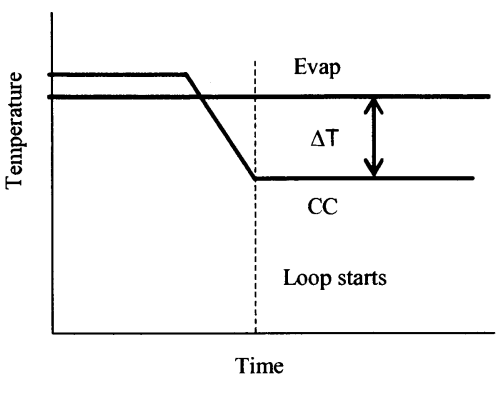

(c)

Figure 3. LHP Start-up

The TEC attached to the CC can maintain a constant CC temperature, and ensure that the evaporator will eventually overcome the required superheat no matter how high the required superheat and how low the heat load are, i.e. the condition shown in Figure 3(a) will prevail. Alternatively, the TEC can be used to lower the CC temperature during the start-up transient to achieve the required superheat as shown in Figure 3(c). Regardless of which method is implemented, the required starter heater power can be substantially reduced or completely eliminated.

Coupling Block: The coupling block is made of a high thermal conductivity metal and is essentially a heat exchanger between the vapor and liquid lines. It allows the liquid returning to the evaporator/CC to absorb heat from the vapor line, which further reduces the control heater power when TEC is heating the CC.

Analytical Models and Scaling Criteria: Part of the technology development for the Thermal Loop experiment is to develop an analytical model which simulates the steady state and transient behaviors of LHPs. The analytical model is based on conservation laws governing the operation of an LHP with multiple evaporators and multiple condensers. The model solves a set of differential equations using Lagrangian method. Inputs to the model include detailed geometries of the LHP components, the evaporator power profiles, and environmental conditions. Outputs of the model are temperature and pressure distributions in the LHP. The model can be used as a stand-alone model for LHP design analysis, or as a subroutine for a general spacecraft thermal analyzer such as SINDA/Fluint [8]. The MLHP experimental data in laboratory and thermal vacuum tests will be correlated with the model predictions to validate the attainment of various TRLs during the course of the Thermal Loop technology development. 
The LHP operation involves some very complicated fluid and thermal processes, which are strongly influenced by gravitational, inertial, viscous, and capillary forces. To obtain better understanding of fluid flow and heat transfer phenomena in an LHP and to provide a means of comparison and generalization of data between different LHPs, some scaling criteria are needed. In addition to the LHP analytical model, a set of dimensional and dimensionless groups has been developed to relate geometry and configuration of the LHP components, properties of the wick and the working fluid, and the environmental conditions surrounding the LHP [9].

Performance Characteristics: Figure 4 illustrates the performance of an MLHP having two evaporators and two condensers. The loop can be started by raising the $\mathrm{CC}$ temperature at a desired temperature that is above the ambient temperature using the TECs so as to flood the evaporators with liquid, and then turning on the instruments. Because the TECs can keep the CC temperature constant, the loop will start. The heat loads to the evaporators can vary independently; both evaporators will yield 100 percent vapor at the same temperature. The two condensers will dissipate the total heat load coming from the evaporators. The load will be automatically distributed between two condensers according to the conservation laws. When an instrument is turned off, part of the heat load from the "on' instrument will flow to the "off" instrument. When both instruments are turned off, the loop can be shut down as long as the $\mathrm{CC}$ temperature is maintained above the minimum allowable instrument temperature, and no heat will be transmitted from the instruments to the radiators.

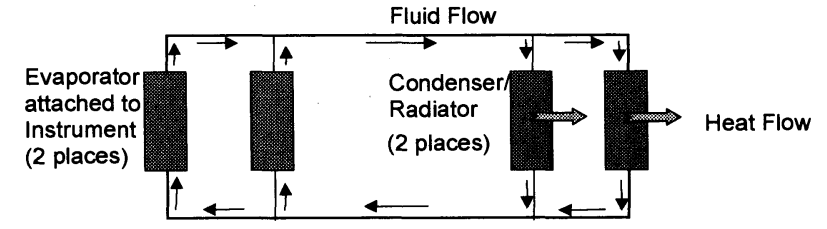

(a) Normal Operation (both instruments on)

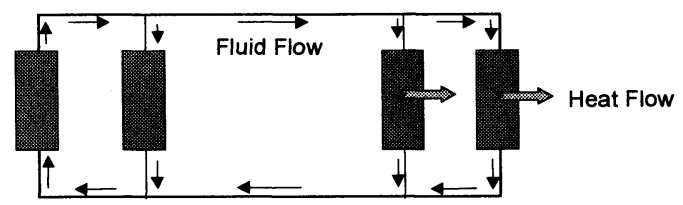

(b) Heat Load Sharing (one instrument on, one off)

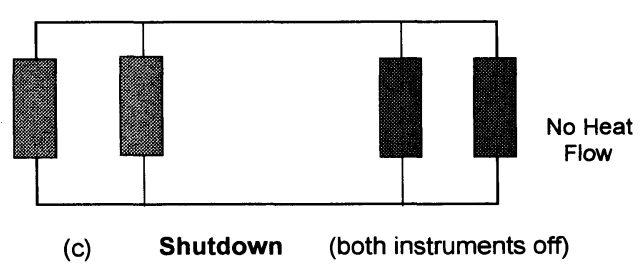

Figure 4. MLHP Operating Modes

\section{Experiment Objectives and Level 1 Requirements}

The MLHP was originally planned to be flown on a ST8 spacecraft before the flight portion was cancelled. The objective of the Thermal Loop experiment is summarized below:

- Verify zero-g performance of an MLHP with multiple evaporators and multiple condensers, and heat load sharing among evaporators in particular. Identify and understand performance differences between one-g and zero-g environments, if any.

- Verify that the MLHP can start reliably and repeatedly in zero-G. Identify and understand differences in start-up transients between one-g and zero-g environments, if any.

- Verify that LHPs with $6.35 \mathrm{~mm}$ OD wicks function in a similar manner as those with $25 \mathrm{~mm}$ OD. Identify and understand performance deviations, if any.

- Verify feasibility of using TECs for LHP startup and operating temperature control. Verify that any or all of the CCs can be used for temperature control, and that control can be switched from one CC to another.

- Verify that use of TECs leads to a significant reduction in auxiliary heater power for LHP startup and operating temperature control.

- Verify the ability of the MLHP analytical model to predicting transient behaviors in zero-g space environment.

Table 2 summarized the current Thermal Loop experiment Level 1 requirements (non-flight) and full and minimum success criteria. Because there is no planned space flight experiment under the ST8 Project, the MLHP Breadboard was ground tested under various orientations so that the gravity effects could be assessed [10]. Furthermore, the analytical modeling is also capable of predicting the gravity effects, and has been used to correlate the experimental results under various test configurations. 
Table 2. Level 1 Requirements and Success Criteria

\begin{tabular}{|c|c|c|}
\hline $\begin{array}{c}\text { Baseline Technology } \\
\text { Validation/Measurement Requirement }\end{array}$ & $\begin{array}{c}\text { Full Project Success } \\
\text { Criteria/Measurement Requirement }\end{array}$ & $\begin{array}{c}\text { Minimum Project Success } \\
\text { Criteria/Measurement Requirement }\end{array}$ \\
\hline $\begin{array}{l}\text { Operate a flight configured, } \\
\text { miniature, multi-evaporator }\end{array}$ & $\begin{array}{l}\text { Heat load-share two loads in } \\
\text { the range of } 0 \text { to } 75 \mathrm{~W} \text { while } \\
\text { loop heat pipe for small } \\
\text { system applications capable of } \\
\text { an } 80 \% \text { success rate on a } \\
\text { minimum of 20 start-ups in a }\end{array}$ & $\begin{array}{l}\text { Heat load-share two loads in } \\
\text { the range of } 0 \text { to } 50 \mathrm{~W} \text { while } \\
\text { the loads either remove or add } \\
\text { heat to the system }\end{array}$ \\
$\begin{array}{l}\text { flight-like environment.. } \\
\text { Develop an analytical model } \\
\text { which can predict the loop's } \\
\text { critical temperatures during } \\
\text { steady state and transient } \\
\text { operation. }\end{array}$ & $\begin{array}{l}\text { Operating temperature of the } \\
\text { Loop measured at the } \\
\text { compensation chamber shall } \\
\text { be within } \pm 3 \mathrm{~K} \text { of the desired } \\
\text { set point temperature over } \\
273 \mathrm{~K} \text { to } 308 \mathrm{~K} \text { range }\end{array}$ & $\begin{array}{l}\text { Operating temperature of the } \\
\text { compensation chamber shall be } \\
\text { within } \pm 5 \mathrm{~K} \text { of the desired set } \\
\text { point temperature over } 273 \mathrm{~K} \text { to } \\
308 \mathrm{~K}^{\circ} \mathrm{C} \text { range }\end{array}$ \\
\end{tabular}

\section{Thermal Vacuum Testing of MLHP Breadboard}

An MLHP Breadboard has been built and tested in laboratory for successful validation of TRL 4 [11-12]. The following discussions focus on the thermal vacuum testing of the MLHP Breadboard for a successful TRL 5 validation.

Figure 5 shows a picture of the MLHP Breadboard. Major design parameters are summarized in Table 3 . The MLHP Breadboard consisted of two parallel evaporators, two parallel condensers, a common vapor transport line and a common liquid return line. A thermal mass of 400 grams of aluminum was attached to each evaporator to simulate the instrument mass. The two parallel condensers were sandwiched between two aluminum plates. A flow regulator consisting of capillary wicks was installed at the downstream of the two condensers. The vapor line and liquid line were connected with several aluminum coupling blocks ( $20 \mathrm{~mm}$ by $20 \mathrm{~mm}$ by $6 \mathrm{~mm}$ each). A TEC was installed on each CC through an aluminum saddle. The other side of the TEC was connected to the evaporator via a copper thermal strap. A close-up view of the evaporator/CC section showing the TECs and thermal straps is depicted in Figure 6. A cartridge heater capable of delivering $1 \mathrm{~W}$ to $200 \mathrm{~W}$ was inserted into each thermal mass. Each TEC was controlled by a bi-polar power supply. Changing the polarity of the power supply changed the TEC operation between the heating and cooling modes.

Table 3. Summary of MLHP Breadboard Design Parameters

\begin{tabular}{|c|c|c|}
\hline Component & Material & Value \\
\hline Evaporators (2) & Aluminum 6061 & $9 \mathrm{~mm}$ O.D. x $52 \mathrm{~mm} \mathrm{~L}$ \\
\hline Primary Wicks (2) & Titanium & $\begin{array}{l}6.35 \mathrm{~mm} \text { O.D. } \times 3.2 \mathrm{~mm} \text { I.D } \\
\text { Pore radius } 1.39 \mu \mathrm{m}(\mathrm{E} 1), 1.47 \mu \mathrm{m}(\mathrm{E} 2) \\
\text { Permeability: } 0.11 \times 10^{-13} \mathrm{~m}^{2}(\mathrm{E} 1), 0.09 \times 10^{-13} \mathrm{~m}^{2}(\mathrm{E} 2)\end{array}$ \\
\hline Secondary Wicks (2) & Stainless Steel & $\begin{array}{l}\text { Pore radius: } 68.7 \mu \mathrm{m} \\
\text { Permeability: } 83 \times 10^{-13} \mathrm{~m}^{2}\end{array}$ \\
\hline Bayonet Tubes (2) & SS 304L & $1.1 \mathrm{~mm}$ O.D. x $0.79 \mathrm{~mm}$ I.D. \\
\hline $\mathrm{CC}(2)$ & SS 304L & $22.2 \mathrm{~mm}$ O.D. $\times 21.2 \mathrm{~mm}$ I.D. $\times 72.4 \mathrm{~mm} \mathrm{~L}$ \\
\hline Vapor Line & SS 304L & $2.38 \mathrm{~mm}$ O.D. $\times 1.37 \mathrm{~mm}$ I.D. $\times 914 \mathrm{~mm} \mathrm{~L}$ \\
\hline Liquid Line & SS 304L & $1.59 \mathrm{~mm}$ O.D. x $1.08 \mathrm{~mm}$ I.D. x $914 \mathrm{~mm} \mathrm{~L}$ \\
\hline Condensers (2) & SS 304L & $2.38 \mathrm{~mm}$ O.D. x $1.37 \mathrm{~mm}$ I.D. $x 2540 \mathrm{~mm} \mathrm{~L}$ \\
\hline Flow Regulator & SS & $\begin{array}{l}\text { Pore radius: } 10.1 \mu \mathrm{m} \\
\text { Permeability: } 3.1 \times 10^{-13} \mathrm{~m}^{2}\end{array}$ \\
\hline Working fluid & Ammonia & 29.3 grams \\
\hline Total LHP mass & & 316.6 grams \\
\hline
\end{tabular}




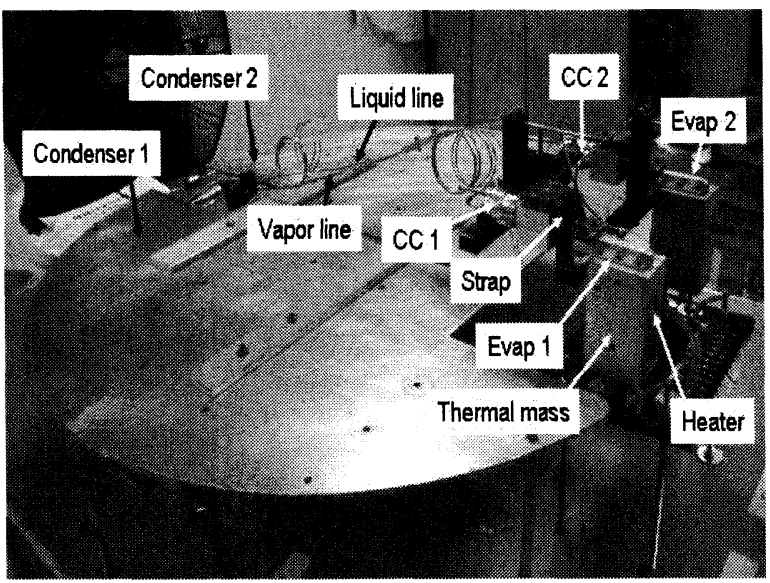

Figure 5. Picture of the MLHP

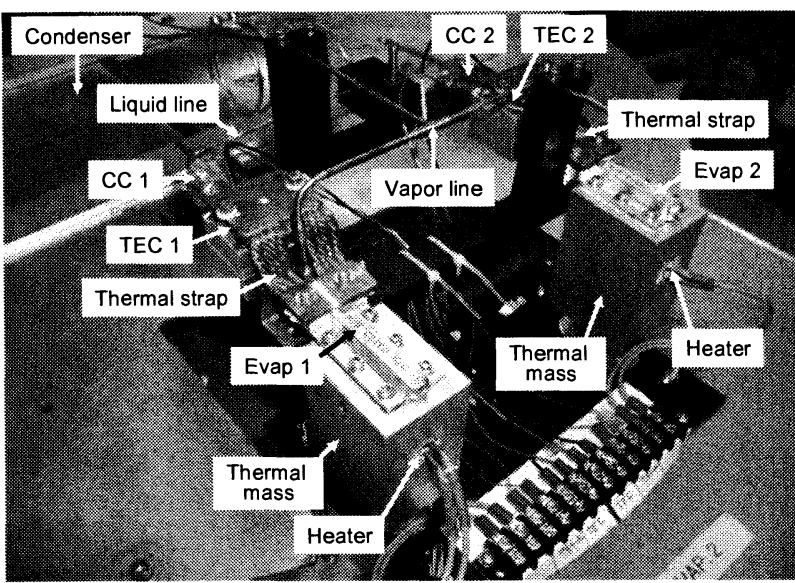

Figure 6. Close-up View of the Evaporator/CC Section

Each condenser plate was exposed to a cryopanel which provided radiative cooling. To facilitate the heat load sharing test, a copper plate was attached to each evaporator thermal mass, and a coolant flow through the thermal mass provided the necessary heat sink. A chiller, located outside the thermal vacuum chamber, was used to circulate the coolant, and two valves were used to direct the flow to the intended thermal mass.

More than 120 type T thermocouples were used to monitor the MLHP and the radiator temperatures, as shown in Figure 7. Several thermocouples other than those shown in Figure 7 were added to the radiators and the cryopanels. A data acquisition system consisting of a data logger, a personal computer, and a screen monitor was used to collect and store temperature and power data every second. Labview software was used for the command and control of the test conditions.

The LHP was tested in the laborartory and in a vacuum chamber, and yielded more than 1200 hours and 500 hours of test data, respctively. Performance of the LHP Breadbord met or exceeded the level 1 requirements. In addition, the LHP analytical model predictions agreed very well with the experiemtnal data. The Thermal Loop experiment has hence attained a TRL of 5. Some experimental results of the thermal vacuum test are highlighted below.

During thermal vacuum testing, a problem was encountered in the ground support equipment, resulting in sporadic data drops. At every event of the data drop, all temperatures read $282 \mathrm{~K}$ for a single data scan. In response to the erroneous CC temperature reading, the TECs would either cool or heat the CC in an attempt to bring the $\mathrm{CC}$ temperature to the desired set point. As a result, the $\mathrm{CC}$ temperature fluctuated about $\pm 1 \mathrm{~K}$ for a few minutes until stable temperatures were reestablished. In the following descriptions of test results, the effect of such data drop can be clearly seen. For clarity, the single

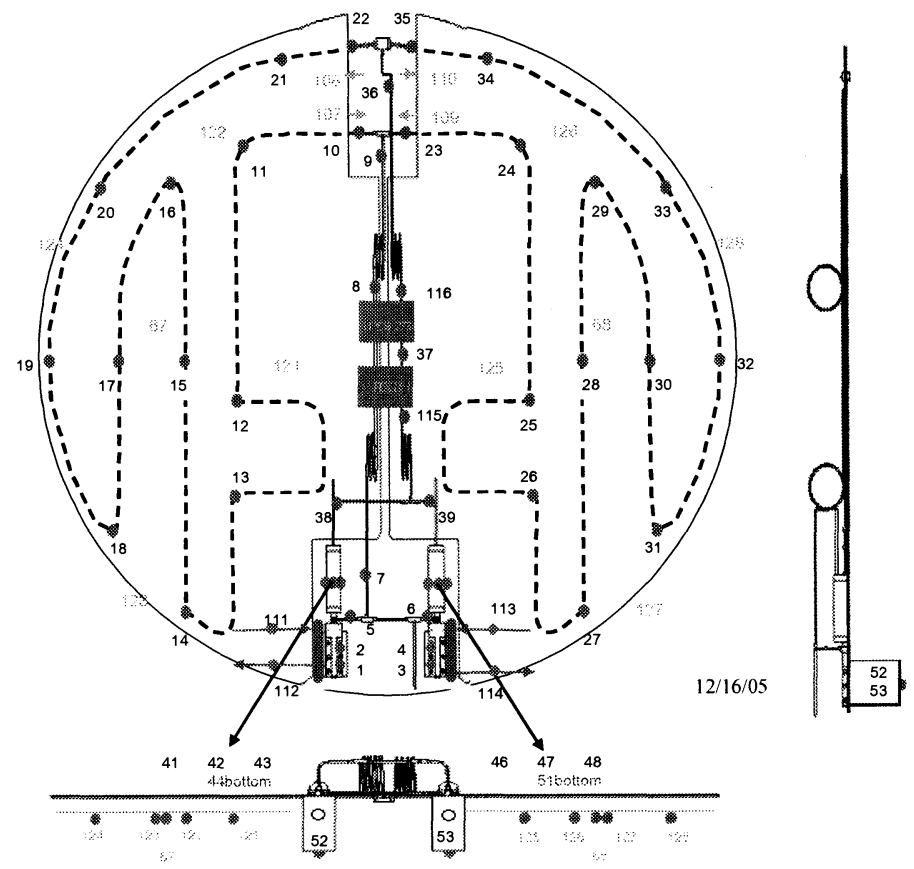

Figure 7. Thermocouple Locations 
point of data drop was removed in all plots. Furthermore, in all plots, numbers in the parentheses denote the thermocouple locations shown in Figure 7.

Figure 8 shows a start-up test where a heat load of $50 \mathrm{~W} / 5 \mathrm{~W}$ was applied to $\mathrm{E} 1 / \mathrm{E} 2$ and the $\mathrm{CC} 2$ temperature was controlled at $293 \mathrm{~K}$. Prior to start-up, the entire loop except $\mathrm{CC} 2$ was completely flooded with liquid. When a heat load of $50 \mathrm{~W} / 5 \mathrm{~W}$ was applied, E1 rose faster in temperature than E2. At the onset of nucleate boiling, E1 had a superheat of $7 \mathrm{~K}$. After vapor was generated in $\mathrm{E} 1$, E2 temperature rose much more quickly as it shared heat from E1. The successful start-up was followed by a power swap from $50 \mathrm{~W} / 5 \mathrm{~W}$ to $5 \mathrm{~W} / 50 \mathrm{~W}$, and the loop continued to work stably.

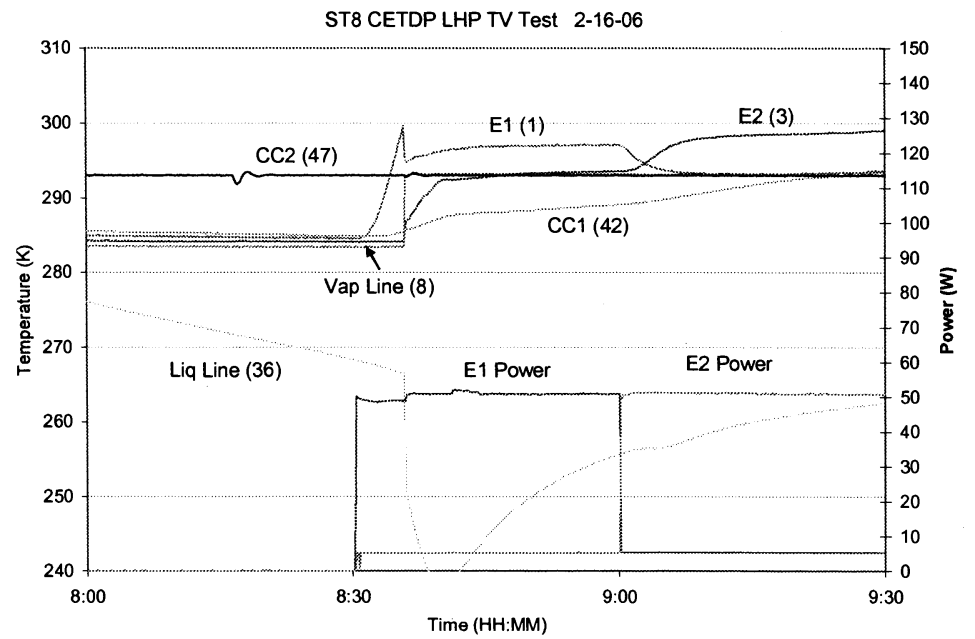

Figure 8. Loop Temperatures for $50 \mathrm{~W} / 5 \mathrm{~W}$ Start-up

Figure 9 shows the experimental data and the analytical model predictions for a start-up. Prior to applying a heat load to $\mathrm{E} 1, \mathrm{CC} 1$ was heated to $303 \mathrm{~K}$ using TEC1. Pre-heating $\mathrm{CC} 1$ caused the E1 temperature to drop, indicating that E1 was flooded with liquid. With a heat load of $5 \mathrm{~W}, \mathrm{E} 1 \mathrm{had}$ a superheat of $1 \mathrm{~K}$ at the onset of start-up. Note that the E2 temperature remained unchanged before the loop started. Once the loop started and vapor was generated, E2 drew heat from E1 by way of heat load sharing and its temperature rose toward the $\mathrm{CC} 1$ saturation temperature. For the model prediction, the experimental data of $1 \mathrm{~K}$ superheat at the onset of start-up was used as an input parameter. In general, the model predications agreed very well with test results. The model also predicted correctly how vapor flowed preferentially to various components during the start-up transient. There was a

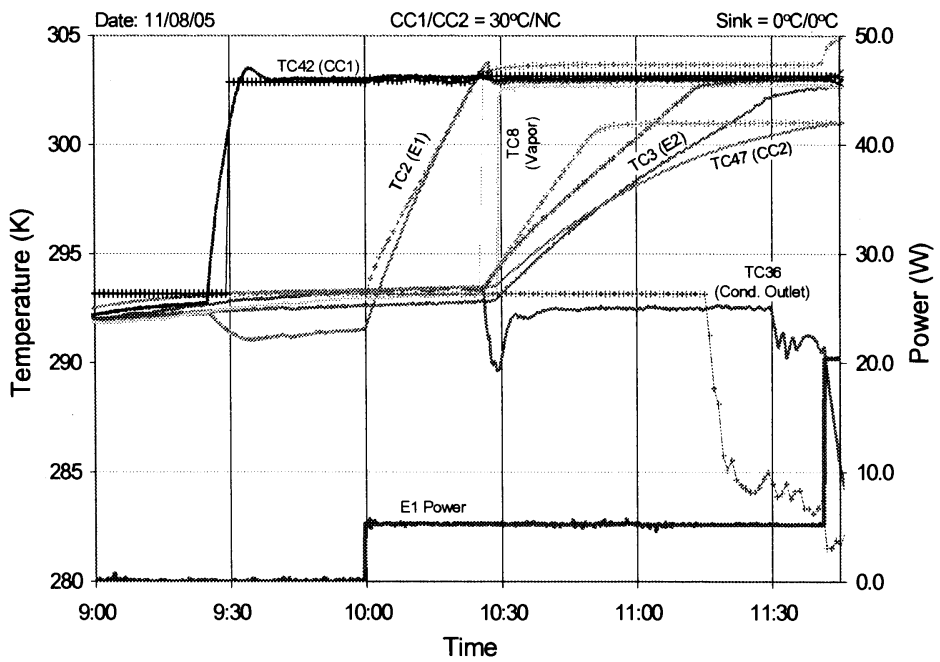

Figure 9. Analytical Model Predictions and Experimental Data for Start-up

shift of time in both figures between the predictions and the experimental data on the moment when E2 reached the saturation temperature and when the liquid line temperature began to drop after the loop started. These discrepancies were caused by the inaccuracy of the model predictions on how much heat was shared during the start-up transient. With a total heat load of only $5 \mathrm{~W}$ into E1, the amount of heat that could be shared by E2 was very small. Any inaccuracy in the model prediction on the heat sharing would result in the inaccuracy of the time it took for E2 to reach the saturation temperature. This was particularly true given that a thermal mass of 400 gram aluminum was attached to each evaporator.

Figure 10 shows the temperatures for a power cycle test where the heat load to E1/E2 was varied as follows: $75 \mathrm{~W} / 0 \mathrm{~W}, 50 \mathrm{~W} / 25 \mathrm{~W}, 25 \mathrm{~W} / 50 \mathrm{~W}, 0 \mathrm{~W} / 75 \mathrm{~W}, 5 \mathrm{~W} / 50 \mathrm{~W}$, and $50 \mathrm{~W} / 5 \mathrm{~W}$. Both cryopanels were maintained at $173 \mathrm{~K}$, and 
both CCs were controlled at $293 \mathrm{~K}$ using TECs. The TECs were able to keep both CCs at $293 \mathrm{~K}$ at all times. The temperatures of E1 and E2 varied with the heat load as expected.

Figure 11 shows the loop temperatures in a high power test. Both CCs were controlled at $308 \mathrm{~K}$ using TECs. The heat load to E1/E2 was $10 \mathrm{~W} / 10 \mathrm{~W}$, and then went up to $60 \mathrm{~W} / 60 \mathrm{~W}$ with $10 \mathrm{~W} / 10 \mathrm{~W}$ increments. The loop demonstrated a heat transport capability of $120 \mathrm{~W}$. The TECs controlled the $\mathrm{CC}$ temperatures within $\pm 0.5 \mathrm{~K}$ at all times except for the periods following data drops where the CC temperature fluctuated about $\pm 1 \mathrm{~K}$ for a short duration before TECs resumed tight control of the CC temperatures. Temperatures of E1/E2 varied with the heat load. At $60 \mathrm{~W} / 60 \mathrm{~W}, \mathrm{E} 1$ began to show partial dry-out as indicated by a large increase of its temperature. As the heat load was reduced to $40 \mathrm{~W} / 40 \mathrm{~W}, \mathrm{E} 1$ recovered from the partial dry-out.

When a condenser is fully utilized, vapor will exit the condenser and flow into the liquid line. The flow regulator in the current two-condenser MLHP was designed to prevent vapor blow through when one of the condensers was fully utilized as long as the other condenser could still dissipate the total heat load.

Figure 12 depicts the loop temperatures during a flow regulation test. Both CCs were controlled at $293 \mathrm{~K}$ using TECs and a constant heat load of $30 \mathrm{~W} / 10 \mathrm{~W}$ was applied to $\mathrm{E} 1 / \mathrm{E} 2$. Tests were conducted by changing the temperature of one cryopanel while keep the other cryopanel at a constant temperature of $223 \mathrm{~K}$. In the first part of the test, the temperature of cryopanel 1 was varied from $223 \mathrm{~K}$ to $293 \mathrm{~K}$ and then to $298 \mathrm{~K}$. When both cryopanels were at $223 \mathrm{~K}$, neither condenser was fully utilized as indicated by the temperatures of both condensers and the liquid exiting the flow regulator. When cryopanel 1 temperature was increased to 293K, condenser 1 dissipated much less heat than condenser 2 . Condenser 2 also rose in temperature because its heat load increased. When the cryopanel 1 temperature was increased to $298 \mathrm{~K}$, above the CC saturation temperature, condenser 1 could no longer

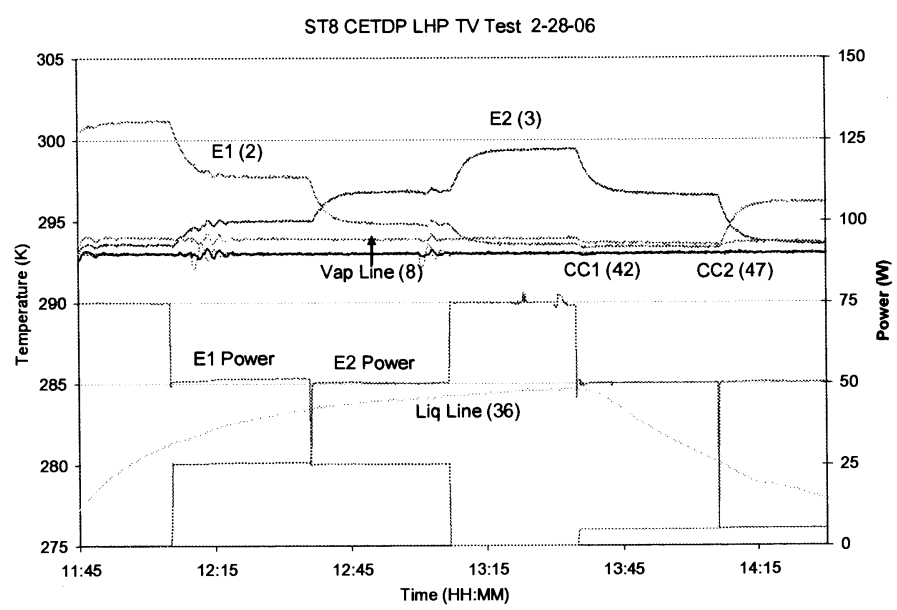

Figure 10. Uneven Power to E1 and E2

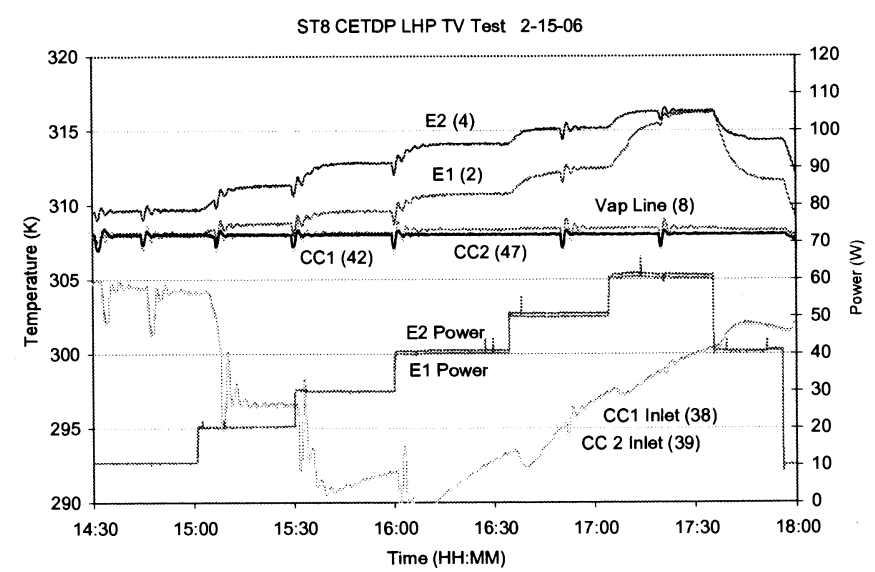

Figure 11. High Power Test

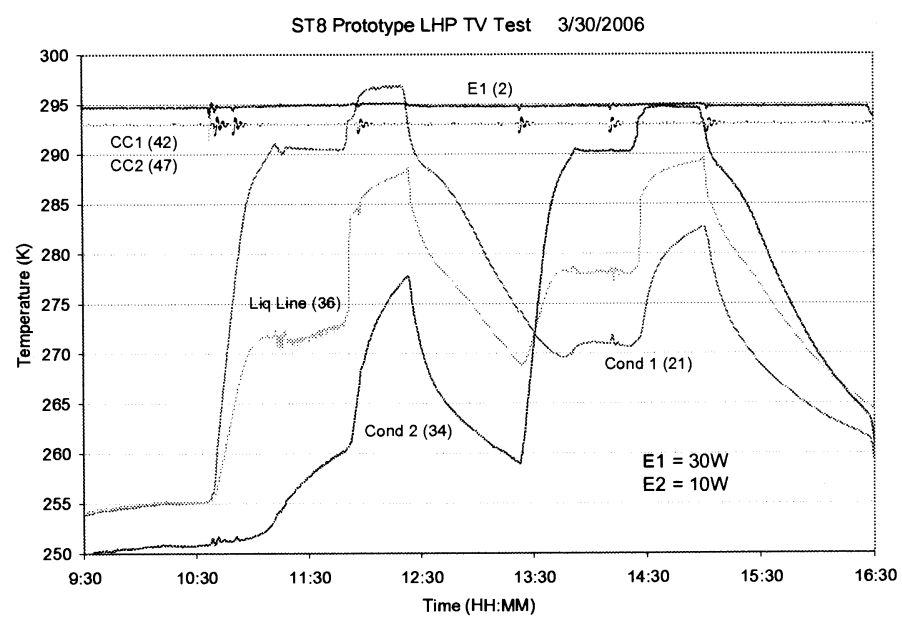

Figure 12. Flow Regulation Test 
dissipate any heat, and vapor passed the exit of condenser 1 . However, the vapor was stopped by the flow regulator, as evidenced by the subcooled temperature of the liquid at the exit of the flow regulator. In the second part of the test, the cryopanel 1 temperature was kept at $223 \mathrm{~K}$ whereas the cryopanel 2 temperature was varied between $223 \mathrm{~K}$ and $298 \mathrm{~K}$. Similar results were observed. This test demonstrated that the flow regulator performed its function as designed.

The heat load sharing test was conducted by changing the following variables one at a time: heat load to the active evaporators that generated the vapor, and the flow rate and temperature of the coolant circulating to the thermal mass of the un-powered evaporator. Figure 13 shows the results of a heat load sharing test. The CC1 temperature was controlled at $303 \mathrm{~K}$ while the $\mathrm{CC} 2$ temperature was not controlled. The two cryopanels were kept at $203 \mathrm{~K}$ and $243 \mathrm{~K}$, respectively. A constant power of $50 \mathrm{~W}$ was applied to E2, and a constant coolant flow rate of $9.45 \mathrm{gram} / \mathrm{s}$ was maintained for the flow circulating the E2 thermal mass. The coolant temperature was initially set at $286 \mathrm{~K}$, followed by step increases with $5 \mathrm{~K}$ increments. The amount of heat shared by E1 was calculated from the coolant mass flow rate and the difference of the coolant temperature at the inlet and outlet of the E1 thermal mass. As the coolant temperature increased, the amount of heat being shared by E1 decreased because the E1 sink had less heat dissipating capability. Moreover, when the coolant temperature increased to $306 \mathrm{~K}$ and $311 \mathrm{~K}$, the heat being shared became negative, meaning that $\mathrm{E} 1$ actually received heat from the coolant and began to work in its normal evaporator mode.

Tests were conducted to demonstrate the power savings using TECs and coupling blocks as compared to using electrical heaters alone. Figure 14 shows the test results using TEC1 and an electrical heater to control the $\mathrm{CC} 1$ temperature at $308 \mathrm{~K}$ at various $\mathrm{E} 1$ heat loads and using 0,2 and 3 coupling blocks. The results show that the TEC could reduce the control heater power by more than 50 percent at all heat loads. The results also show that the coupling blocks were effective in reducing the control heater power whether a TEC or an electrical heater was used. The combination of a TEC and coupling blocks yielded the highest power savings. Furthermore, when a TEC was used, there was no further power savings by increasing the number of coupling blocks from 2 to 3 .

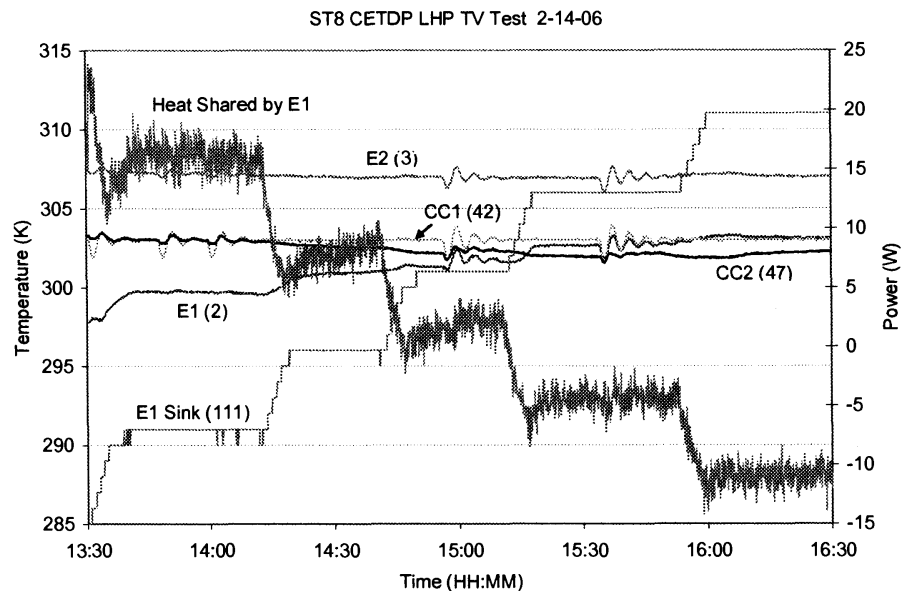

Figure 13. Heat Load Sharing Operation

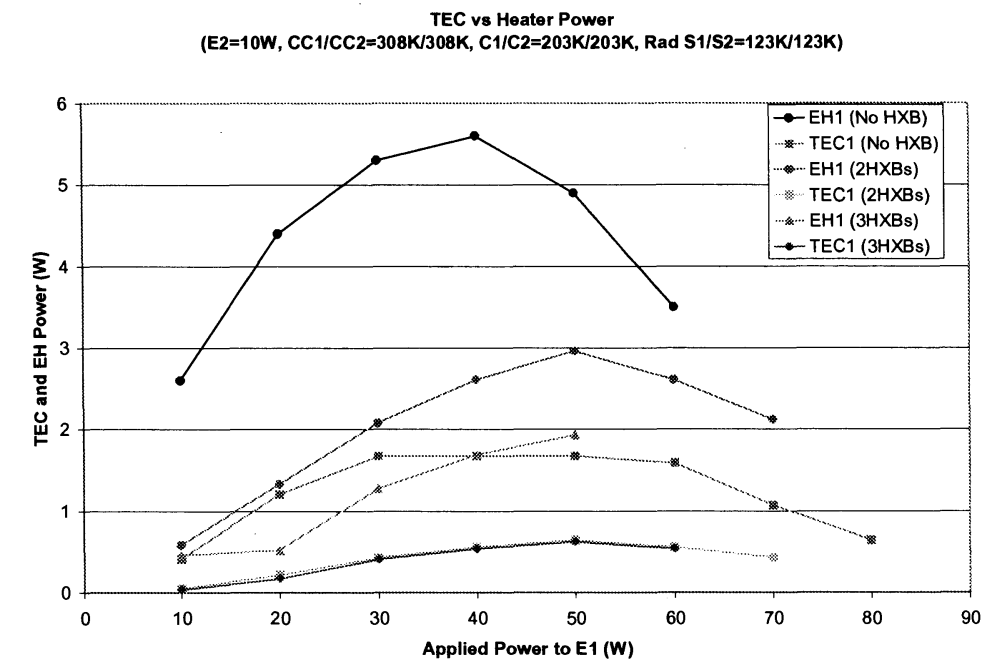

Figure 14. Flow Regulation Test

In addition to saving the $\mathrm{CC}$ control heater power, the TECs had advantages over electrical heaters by providing cooling to the $\mathrm{CC}$ and affording the loop to operate below its natural operating temperatures. Several tests were conducting with the loop operating successfully at $273 \mathrm{~K}$ or lower. 
Table 4 shows the comparison of the TRL 5 validation results and the performance requirements of the Thermal Loop experiment. The TRL 5 validation results verified that the MLHP protoflight MLHP design will meet or exceed the Level 1 requirements.

Table 4. TRL 5 Validation Results for Protoflight MLHP Design Verification

\begin{tabular}{|c|c|c|c|}
\hline Test & Requirements & TRL 5 Test Results & Compliance \\
\hline Start-up & $\begin{array}{l}\text { - An } 80 \% \text { success rate or better } \\
\text { on a minimum of } 20 \text { start-ups } \\
\text { Demonstrate over a } \\
\text { temperature range between } \\
273 \mathrm{~K} \text { and } 308 \mathrm{~K}\end{array}$ & $\begin{array}{l}\text { - } 100 \% \text { success on } 72 \text { start-up tests } \\
\text { - Temperature range between } 258 \mathrm{~K} \text { and } \\
308 \mathrm{~K}\end{array}$ & $\begin{array}{l}\text { Exceed } \\
\text { requirements }\end{array}$ \\
\hline $\begin{array}{l}\text { Heat } \\
\text { Transport }\end{array}$ & - $75 \mathrm{~W}$ total heat load & - $\quad 120 \mathrm{~W}$ total heat load & $\begin{array}{l}\text { Exceed } \\
\text { requirements }\end{array}$ \\
\hline Operation & $\begin{array}{l}\text { Control the loop saturation } \\
\text { temperature within } \pm 3 \mathrm{~K} \\
\text { between } 273 \mathrm{~K} \text { and } 308 \mathrm{~K} \\
\text { Transient operation over full } \\
\text { range of heat loads }\end{array}$ & $\begin{array}{l}\text { - Control the loop saturation temperature } \\
\text { within } \pm 0.5 \mathrm{~K} \text { between } 258 \mathrm{~K} \text { and } 308 \mathrm{~K} \\
\text { Transient operation between } 5 \mathrm{~W} \text { and } \\
120 \mathrm{~W} \text { with rapid changes of heat load } \\
\text { and/or sink temperature } \\
\text { Changed saturation temperature between } \\
258 \mathrm{~K} \text { and } 308 \mathrm{~K} \text { while in operation }\end{array}$ & $\begin{array}{l}\text { Exceed } \\
\text { requirements }\end{array}$ \\
\hline $\begin{array}{l}\text { Heat Load } \\
\text { Sharing }\end{array}$ & $\begin{array}{l}\text { Demonstrate heat load sharing } \\
\text { between two evaporators (0W } \\
\text { to } 75 \mathrm{~W})\end{array}$ & $\begin{array}{l}\text { Heat load sharing was demonstrated by } \\
\text { changing } 1) \text { heat load to one evaporator } \\
(0 \mathrm{~W} \text { to } 100 \mathrm{~W}) ; 2) \text { sink temperature of } \\
\text { un-powered evaporator; and } 3) \mathrm{CC} \\
\text { saturation temperature }\end{array}$ & $\begin{array}{l}\text { Exceed } \\
\text { requirements }\end{array}$ \\
\hline $\begin{array}{l}\text { LHP Model } \\
\text { Correlation }\end{array}$ & $\begin{array}{l}\text { Model predictions of LHP } \\
\text { critical temperatures within } \\
\pm 5 \mathrm{~K} \text { of the test results during } \\
\text { steady state and transient } \\
\text { operation }\end{array}$ & $\begin{array}{l}\text { Model predictions of the loop critical } \\
\text { temperatures (CCs, evaporators, vapor } \\
\text { line) were within } \pm 5 \mathrm{~K} \text { of the test results } \\
\text { during steady state and transient } \\
\text { operation. }\end{array}$ & $\begin{array}{l}\text { Meet } \\
\text { requirement }\end{array}$ \\
\hline
\end{tabular}

\section{MLHP Protoflight Unit}

A MLHP protoflight unit as shown in Figure 15 has been built although the flight experiment portion of the ST8 Project was cancelled. Major design parameters of the protoflight unit are summarized in Table 5. The protoflight unit is being tested in a thermal vacuum chamber for TRL 6 validation. Preliminary results show that it will meet all the Level 1 requirements. Figure 16 shows the layout of the Thermal Loop experiment as it was originally designed to fly on the ST8 spacecraft. After a successful validation of TRL 6 , the protoflight unit will be ready for a space flight experiment should opportunities

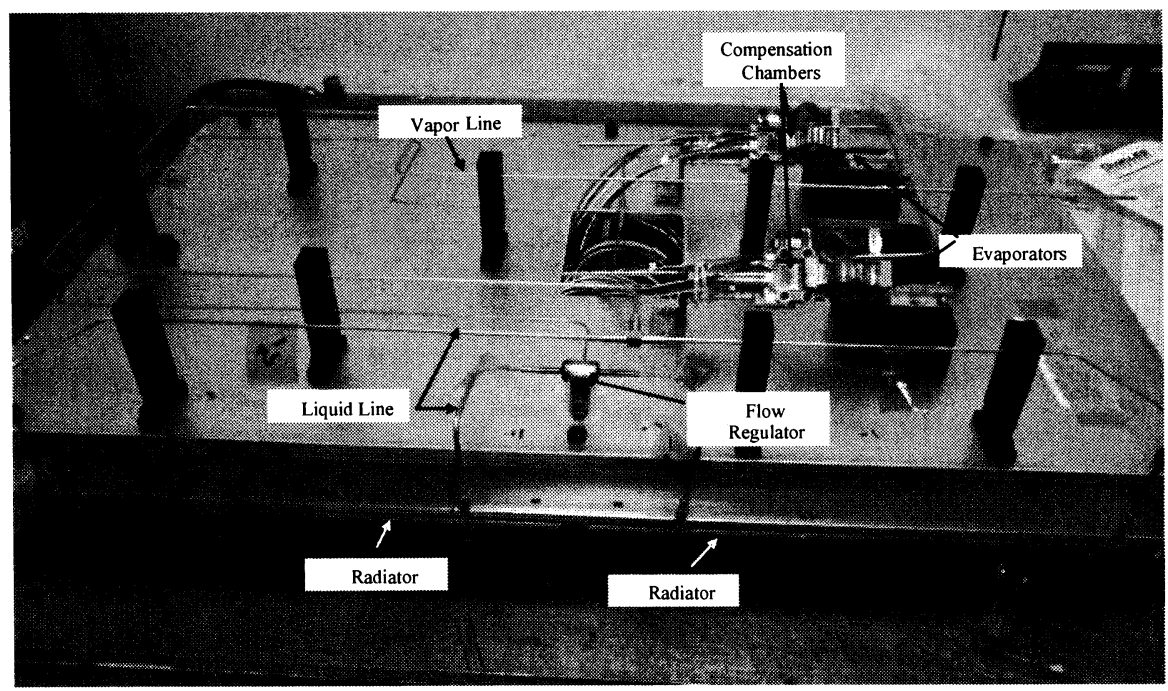

Figure 15. MLHP Protoflight Unit arise. 
Table 5. Summary of MLHP Protoflight Unit Design Parameters

\begin{tabular}{|c|c|c|}
\hline Component & Material & Value \\
\hline Evaporators (2) & Aluminum 6061 & $9 \mathrm{~mm}$ O.D. x $52 \mathrm{~mm} \mathrm{~L}$ \\
\hline Primary Wicks (2) & Titanium & $\begin{array}{l}\text { 6.35 mm O.D. } \times 3.2 \mathrm{~mm} \text { I.D } \\
\text { Pore radius } 1.25 \mu \mathrm{m}(\mathrm{E} 1), 1.20 \mu \mathrm{m}(\mathrm{E} 2) \\
\text { Permeability: } 0.8 \times 10^{-14} \mathrm{~m}^{2}(\mathrm{E} 1), 1.0 \times 10^{-14} \mathrm{~m}^{2}(\mathrm{E} 2)\end{array}$ \\
\hline Secondary Wicks (2) & Stainless Steel & $\begin{array}{l}\text { Pore radius: } 68.7 \mu \mathrm{m} \\
\text { Permeability: } 83 \times 10^{-13} \mathrm{~m}^{2}\end{array}$ \\
\hline Bayonet Tubes (2) & SS 304L & $1.1 \mathrm{~mm}$ O.D. $\times 0.80 \mathrm{~mm}$ I.D. \\
\hline $\mathrm{CC}(2)$ & SS 304L & $22.5 \mathrm{~mm}$ O.D. $\times 21.2 \mathrm{~mm}$ I.D. $\times 76.7 \mathrm{~mm} \mathrm{~L}$ \\
\hline Vapor Line & SS 304L & $2.38 \mathrm{~mm}$ O.D. $x 1.37 \mathrm{~mm}$ I.D. $\times 1580 \mathrm{~mm} \mathrm{~L}$ \\
\hline Liquid Line & SS 304L & $1.59 \mathrm{~mm}$ O.D. $x 1.08 \mathrm{~mm}$ I.D. $x 1102 \mathrm{~mm} \mathrm{~L}$ \\
\hline Condensers (2) & SS 304L & $2.38 \mathrm{~mm}$ O.D. x $1.37 \mathrm{~mm}$ I.D. x $1676 \mathrm{~mm} \mathrm{~L}$ (each) \\
\hline Flow Regulator & SS & $\begin{array}{l}\text { Pore radius: } 11.59 \mu \mathrm{m} \\
\text { Permeability: } 9.3 \times 10^{-13} \mathrm{~m}^{2}\end{array}$ \\
\hline Working Fluid & Ammonia & 31.3 grams \\
\hline Total MLHP mass & & 4,721 grams \\
\hline
\end{tabular}

\section{Conclusion}

Under NASA's New Millennium Program ST8 Project, an MLHP with two miniature evaporators and two condensers has been developed as a versatile two-phase heat transport system. The MLHP combines the functions of variable conductance heat pipes, thermal switches, thermal diodes, and the state-of-the-art LHPs into a single integrated thermal system. It retains all features of state-of-the-art LHPs and offers additional advantages to enhance the functionality, performance, versatility, and reliability of the system.

An MLHP Breadboard has been tested in the laboratory and thermal vacuum environments, and demonstrated excellent performance. An analytical model has also been developed to predict the steady state and transient performance of the MLHP. The analytical model predictions correlated well with LHP Breadboard experimental results. A protoflight unit has been built, and is being tested in a thermal vacuum chamber for TRL 6 validation.

The performance of two-phase devices is known to be strongly influenced by gravity. The large time constant involved in heat transfer requires a long-duration space flight experiment to verify the zero-G performance of the MLHP. Successful flight validation will bring the benefits of MLHP technology to future missions requiring low mass, low-power and compact spacecraft. It will also reduce the risk for first users.

\section{References}

1. Maidanik, Y., and Fershtater, Y., "Theoretical Basis and Classification of Loop Heat Pipes and Capillary Pumped Loops," $10^{\text {th }}$ International Heat Pipe Conference, Stuttgart, Germany, 1997.

2. Ku, J., "Operating Characteristics of Loop Heat Pipes," SAE Paper No. 1999-01-2007, 29 ${ }^{\text {th }}$ International Conference on Environmental Systems, Society of Automotive Engineers, Denver, Colorado, July 12-15, 1999.

3. Baker, C and Grob, E., "System Accommodation of Propylene Loop Heat Pipes for The Geoscience Laser Altimeter System Instrument," SAE paper No. 2001-01-2263, 2001.

4. Ottenstein, L., Ku, J., and Feenan, D., "Thermal Vacuum Testing of a Novel Loop Heat Pipe Design for the Swift BAT Instrument," STAIF-2003, Albuquerque, New Mexico, February 2-6, 2003.

5. Choi, M., "Thermal Vacuum/Balance Test Results of Swift BAT with Loop Heat Pipe Thermal System," AIAA Paper No. 2004-5683, $2^{\text {nd }}$ Intersociety Energy Conversion Engineering Conference, Providence, Rhode Island, August 16-19, 2004.

6. Ku, J., "Heat Load Sharing in a Loop Heat Pipe with Multiple Evaporators and Multiple Condensers," AIAA Paper No. AIAA-2006-3108, $9^{\text {th }}$ AIAA/ASME Joint Themophysics and Heat Transfer Conference, San Francisco, CA, June 5-8, 2006.

7. Ku, J. and Birur, G., "An Experimental Study of the Operating Temperature in a Loop Heat Pipe with Two Evaporators and Two Condensers," SAE Paper No. 2001-01-2189, 31 ${ }^{\text {st }}$ International Conference on Environmental Systems, Society of Automotive Engineers, Orlando, Florida, July 9-12, 2001. 
8. SINDA/FLUINT User's Manual - Version 4.0, Cullimore and Ring Technologies, Inc., 1997.

9. Mishkins, D., Ochterbeck, J., Sodtke, C., Ku, J., and D. Butler, "Non-dimensional Analysis and Scaleing Issues in Loop Heat Pipes", $41^{\text {st }}$ AIAA Aerospace Science Meeting and Exhibit, Reno, Nevada, January 6-9, 2003.

10. Ku, J. and Nagano, H., "Effects of Gravity on Start-up and Heat Load Sharing of a Miniature Loop Heat Pipe," SAE Paper No. 2007-01-3234, 37 $7^{\text {th }}$ International Conference on Environmental Systems, Chicago, Illinois, July 9-12, 2007.

11. . Ku, J., Ottenstein, L., Butler, D. and Nagano, H., "Thermal Performance of a Miniature Loop Heat Pipe with Multiple Evaporators and Multiple Condensers,“ $14^{\text {th }}$ International Heat Pipe Conference, Florianópolis, Brazil, April 22-27, 2007.

12. Ku, J. and Nagano, H., "Loop Heat Pipe Operation with Thermoelectric Converters and Coupling Blocks," AIAA Paper No. AIAA-2007-4713, $5^{\text {th }}$ Intersociety Energy Conversion Engineering Conference, St. Louis, Missouri, June 25-27, 2007

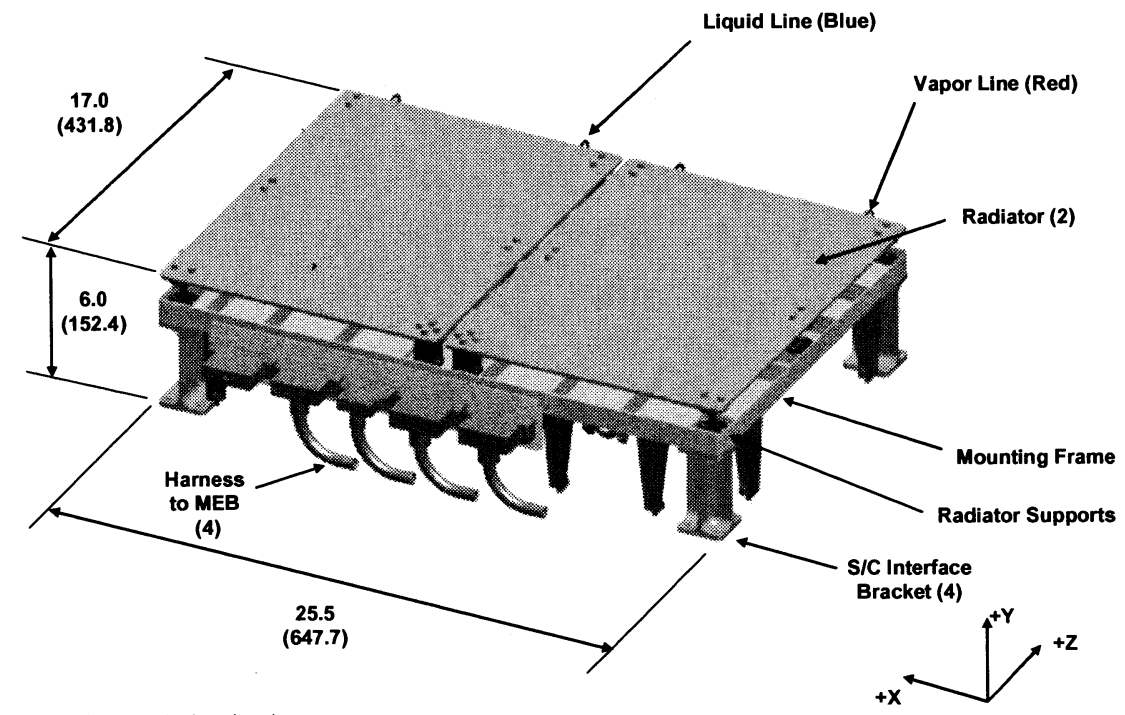

All Dimensions are inches $(\mathrm{mm})$

(a) View from Space

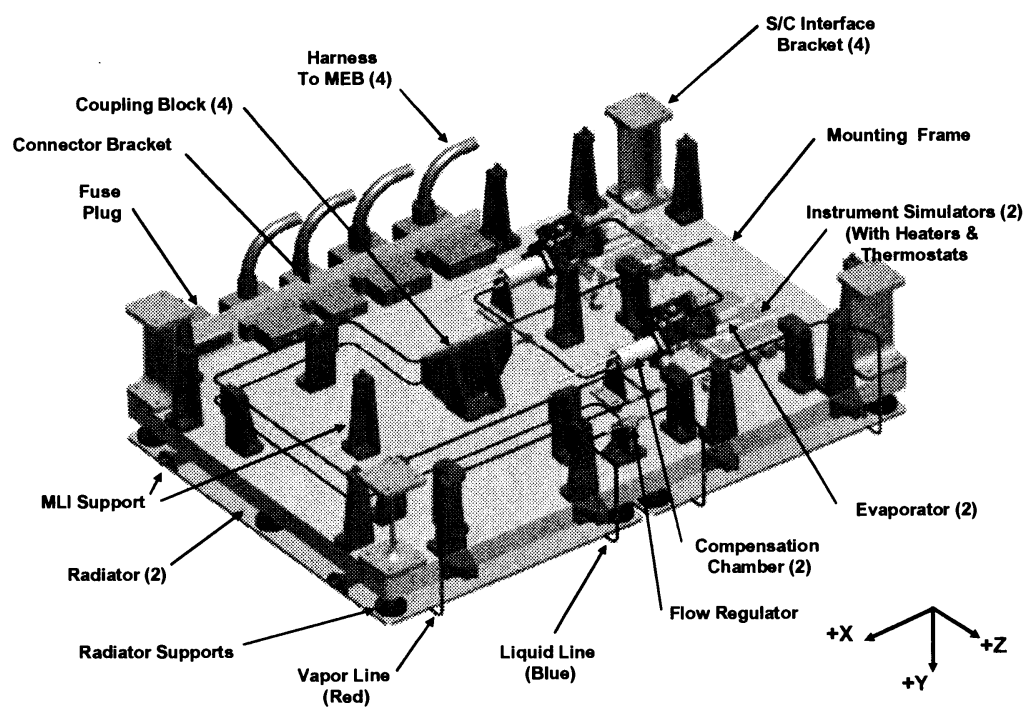

(b) View from Spacecraft

Figure 16. MLHP Flight Experiment Layout 